\title{
LAMINAR FORCED CONVECTION HEAT TRANSFER OVER STAGGERED CIRCULAR TUBE BANKS: A CFD APPROACH
}

\author{
Tahseen A. Tahseen ${ }^{1,2}$, M. Ishak ${ }^{2,3}$ and M. M. Rahman ${ }^{2,3}$ \\ ${ }^{1}$ Department of Mechanical Engineering, College of Engineering, \\ University of Tikrit, Tikrit, Iraq \\ Email: tahseen444@gmail.com; mustafizur@ump.edu.my \\ ${ }^{2}$ Faculty of Mechanical Engineering, University Malaysia Pahang \\ 26600 Pekan, Pahang, Malaysia \\ Phone : +609-424-2246; Fax : +609-424-2202 \\ ${ }^{3}$ Automotive Engineering Centre, Universiti Malaysia Pahang, \\ 26600 Pekan, Pahang, Malaysia.
}

\begin{abstract}
This paper presents the numerical study of two-dimensional forced convection heat transfer for staggered tube banks in cross flow under incompressible, steady-state conditions. This system is solved for body-fitted coordinates using the finite volume method for flow over a bundle of cylindrical tubes. A constant heat flux is imposed on the surface of the tubes as the thermal boundary condition. The type of arrangement considered is a set of staggered tubes. Ratios of longitudinal pitch to tube diameter $\left(S_{T} / D\right)$ of $1.25,1.5$, and 2 are considered. Reynolds numbers are varied from 25 to 250 and the Prandtl number is taken as 0.71 . Velocity field vectors, temperature contours, and the local and average Nusselt numbers are analyzed in this paper. It can be seen that the predicted results are in good agreement with experimental and numerical results obtained previously. The obtained results show that the heat transfer rate increases with a reduction in the step of the longitudinal tube diameter. The local heat transfer depends strongly on the Reynolds number. The highest values are obtained at the surface opposite to the direction of flow. The heat transfer rate is insignificant in the areas of recycling.
\end{abstract}

Keywords: Forced convection; cylindrical tube; staggered arrangement; body-fitted coordinates; finite volume method.

\section{INTRODUCTION}

The flow of fluids and the heat transfer in tube banks represent an idealization of many industrially important processes. Tube bundles are employed widely in cross-flow heat exchangers; the design of which is still based on empirical correlations of heat transfer and pressure drop. Heat exchangers with tube banks in cross-flow are of great practical interest in many thermal and chemical engineering processes (Buyruk, 2002; Mandhani, Chhabra, \& Eswaran, 2002; Incropera, Dewitt, Bergman, \& Lavine, 2007; Liang \& Papadakis, 2007; Al-Doori, 2011; Syam Sundar \& Sharma, 2011; Naga Sarada, Sita Rama Raju, Kalyani Radha, \& Syam Sunder, 2012). There have been several twodimensional numerical studies of pressure drop, heat transfer, and incompressible laminar flow for staggered tube arrays in cross-flow (Yuan, Tao, \& Wang, 1998; Rahmani, Mirzaee, \& Shirvani, 2005; Khan, Culham, \& Yovanovich, 2006; Marchi \& Hobmeir, 2007). A low Reynolds number and a Prandtl number equal to 0.71 have been 
considered in general (Chang, Beris, \& Michaelides, 1989; Wang \& Georgiadis, 1996). An experimental study was carried out to investigate the heat transfer and the flow characteristics from one tube within a staggered tube bundle and within a row of similar tubes. Variation of a local Nusselt number and local pressure coefficients were shown with different blockages and Reynolds numbers (Buyruk, Johnson, \& Owen, 1998; Buyruk, 1999; Matos, Vargas, Laursen, \& Saboya, 2001; Matos, Vargas, Laursen, \& Bejan 2004). Experimental and numerical studies of pressure drop and heat transfer through bundles of parallel cylinders have been performed, in which the numerical results cover the range $1 \leq \operatorname{Re}_{D} \leq 30,0.72 \leq \operatorname{Pr} \leq 100,0.6 \leq \phi \leq 0.95$, and $0 \leq \beta \leq 60^{\circ}$, where $\phi$ is the porosity of the bundle as a saturated porous medium and $\beta$ is the angle to the cylinder centerline. Experimental measurements have been obtained in the range of $1 \leq R e_{D} \leq 30,0.84 \leq \phi \leq 0.92$, and $0 \leq \beta \leq 60$. The results show that significant errors may occur if the available large $R e_{D}$ information is extrapolated to the domain covered by this study (Fowler \& Bejan, 1994). This is an experimental, numerical and analytical study of the optimal spacing between cylinders in cross-flow forced convection. The experimental $R e_{D}$ range is 50-4000, and in the second part, similar results are developed based on numerical simulations for $\operatorname{Pr}=0.72$ and $40 \leq R e_{D} \leq 200$. The experimental and numerical results for optimal spacing and maximum thermal conductance are explained and correlated analytically by intersecting the small- and large-spacing asymptotes of the thermal conductance function (Stanescu, Fowler, \& Bejan, 1996; Rosdzimin, Zuhairi, \& Azwadi, 2010). A calculation procedure for two-dimensional elliptic flow is applied to predict the pressure drop and the heat transfer characteristics of laminar and turbulent flow of air across the tube banks. The theoretical results of the present model are compared with previously published experimental data (Wilson \& Bassiouny, 2000). Cross-flow over tube banks is commonly encountered in practice in heat transfer equipment. The average Nusselt number increases by more than $30 \%$ and $65 \%$ on the second and third tubes, respectively, in comparison with that of the first tube (Yoo, Kwonb, \& Kim, 2007). Tahseen, Ishak \& Rahman (2012a,b, 2013) presented numerical studies of incompressible, steady-state flow using body-fitted coordinates. The first study considers heat transfer over two flat staggered tubes and the second study considers heat transfer over an in-line bank of circular tubes. The two studies show the effect of the Reynolds number on the Nusselt number, and that the Nusselt number increases with an increase of Reynolds number. The objective of this study is the numerical simulation of two-dimensional laminar incompressible flow and heat transfer over a staggered circular tube bank. The local and average heat transfer characteristics for staggered tube banks are investigated in the present study.

\section{METHODOLOGY}

The investigated problem is a two-dimensional staggered tube bank with tube diameters of $15 \mathrm{~mm}$ and with the longitudinal distance between two consecutive tubes $\left(S_{L}\right)$ of 15 $\mathrm{mm}$. The equations governing the conservation of continuity, momentum, and energy, in Cartesian vector notation, assume constant thermophysical properties of the fluid for steady-state incompressible flow. The physical system considered in the present study is displayed in Figure 1 (Bejan, 2004):

Continuity Equation: $\frac{\partial U}{\partial X}+\frac{\partial V}{\partial Y}=0$ 
Momentum (Navier-Stokes):

X-direction (u momentum) $U \frac{\partial V}{\partial X}+V \frac{\partial V}{\partial Y}=-\frac{\partial P}{\partial X}+\frac{1}{\operatorname{Re}_{D}}\left[\frac{\partial^{2} U}{\partial X^{2}}+\frac{\partial^{2} U}{\partial Y^{2}}\right]$

Y-direction (v momentum) $U \frac{\partial V}{\partial X}+V \frac{\partial V}{\partial Y}=-\frac{\partial P}{\partial X}+\frac{1}{\operatorname{Re}_{D}}\left[\frac{\partial^{2} V}{\partial X^{2}}+\frac{\partial^{2} V}{\partial Y^{2}}\right]$

Energy:

$$
U \frac{\partial \theta}{\partial X}+V \frac{\partial \theta}{\partial Y}=\frac{1}{\operatorname{Pr} \operatorname{Re}_{D}}\left[\frac{\partial^{2} \theta}{\partial X^{2}}+\frac{\partial^{2} \theta}{\partial Y^{2}}\right]
$$

The dimensionless variables have been defined based on appropriate physical scales as Eq. (5):

$$
\left.\begin{array}{l}
(X, Y)=\frac{(x, y)}{D}, P=\frac{p}{\rho\left(U_{\infty}\right)^{2}},(U, V)=\frac{(u, v)}{U_{\infty}}, \\
\theta=\frac{T-T_{\infty}}{T_{w}-T_{\infty}}, \operatorname{Re}_{D}=\frac{U_{\infty} D}{v}, \operatorname{Pr}=\frac{C_{P} \mu}{k}
\end{array}\right\}
$$

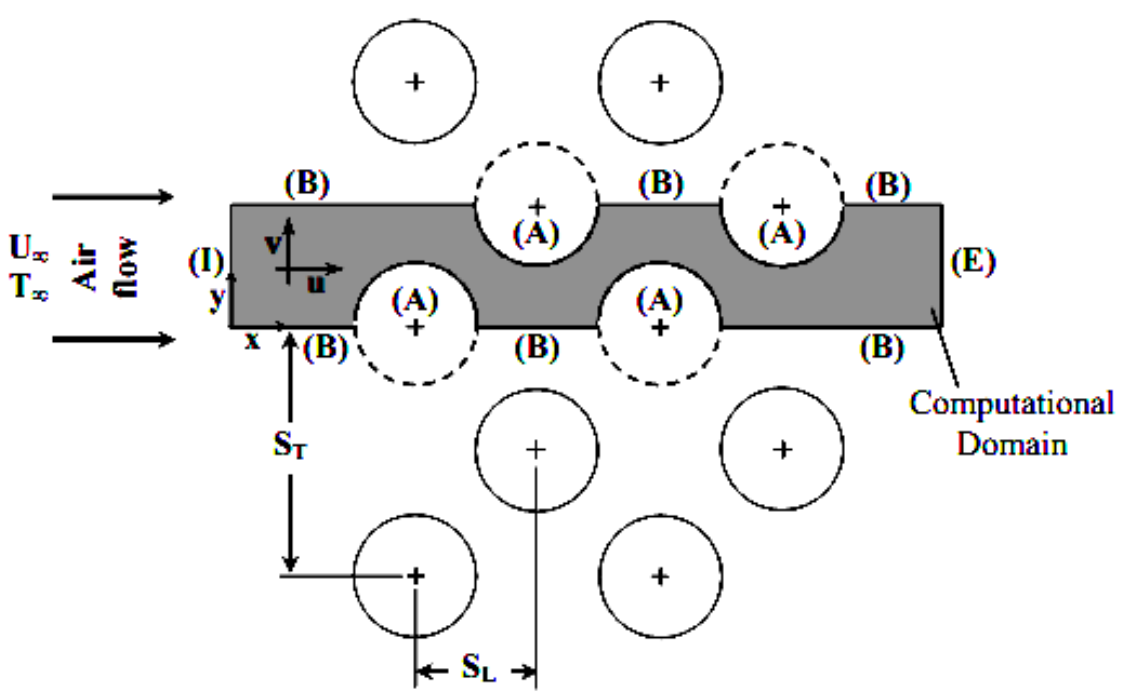

Figure 1. Schematic of staggered tube banks and computational domain.

The schematic of staggered tube banks and the computational domain are shown in Figure 1. The boundary conditions are as follows:
(A) $\quad U=V=0, \quad \theta=1$
(B) $\quad \frac{\partial U}{\partial Y}=0, \quad V=0, \quad \frac{\partial \theta}{\partial Y}=0$
(E) $\frac{\partial U}{\partial X}=\frac{\partial V}{\partial X}=0, \frac{\partial \theta}{\partial X}=0$
(I) $\quad U=1, \quad \frac{\partial V}{\partial X}=0, \quad \theta=0$ 
The heat transfer coefficient $(h)$ can be expressed in dimensionless form by the local and average Nusselt numbers, $\mathrm{Nu}$ and $\overline{\mathrm{Nu}}$, which are defined as Eq. (6) (Chen \& Wung, 1989):

$$
N u=\frac{h D}{k}=\left.\frac{\partial \varphi}{\partial n}\right|_{\varphi}, \quad \overline{N u}=\frac{\bar{h} D}{k}=\left(\int_{\varphi} N u d s\right) /\left(\int_{\varphi} d s\right)
$$

The set of conservation Eqs. (2-5) can be written in general form in Cartesian coordinates as Eq. (7):

$$
\frac{\partial(U \phi)}{\partial X}+\frac{\partial(V \phi)}{\partial Y}=\frac{\partial}{\partial X}\left(\Gamma \frac{\partial \phi}{\partial X}\right)+\frac{\partial}{\partial Y}\left(\Gamma \frac{\partial \phi}{\partial Y}\right)+S_{\phi}
$$

The continuity equation, Eq. (1) has no diffusion and source terms. It will be used to derive an equation for the pressure correction. The grid generation scheme based on elliptic partial differential equations is used in this study to generate the curvilinear coordinates. Eq. (7) can be transformed from the physical domain to the computational domain according to the following transformation $\varsigma=\varsigma(x, y), \eta=\eta(x, y)$ (Thompson, Warsi, \& Martin, 1985). The final form of the transformed equation can be written as Eq. (8):

$$
\frac{\partial}{\partial \varsigma}\left(\phi G_{1}\right)+\frac{\partial}{\partial \eta}\left(\phi G_{2}\right)=\frac{\partial}{\partial \varsigma}\left(\frac{\Gamma}{J}\left(\alpha \frac{\partial \phi}{\partial \varsigma}-\gamma \frac{\partial \phi}{\partial \eta}\right)\right)+\frac{\partial}{\partial \eta}\left(\frac{\Gamma}{J}\left(\beta \frac{\partial \phi}{\partial \eta}-\gamma \frac{\partial \phi}{\partial \varsigma}\right)\right)+J S_{\phi}
$$

where

$$
\left.\begin{array}{l}
G_{1}=U \frac{\partial Y}{\partial \eta}-V \frac{\partial X}{\partial \eta}, \quad G_{2}=V \frac{\partial X}{\partial \varsigma}-U \frac{\partial Y}{\partial \varsigma}, \quad J=\left(\frac{\partial X}{\partial \varsigma} \frac{\partial Y}{\partial \eta}-\frac{\partial Y}{\partial \varsigma} \frac{\partial X}{\partial \eta}\right) \\
\alpha=\left(\frac{\partial x}{\partial \eta}\right)^{2}+\left(\frac{\partial y}{\partial \eta}\right)^{2}, \quad \gamma=\left(\frac{\partial x}{\partial \varsigma} \frac{\partial x}{\partial \eta}\right)+\left(\frac{\partial y}{\partial \varsigma} \frac{\partial y}{\partial \eta}\right), \quad \beta=\left(\frac{\partial x}{\partial \varsigma}\right)^{2}+\left(\frac{\partial y}{\partial \varsigma}\right)^{2}
\end{array}\right\}
$$

Eq. (8) was solved numerically by using a control volume-based finite difference method. It was solved by the marching type procedure that involves a series of twodimensional elliptic problems in the cross-stream plane. The marching step size is $1 \times 10^{-4}$ along the axial distance. At each marching step, the strong coupling of pressure and velocity in the cross section was calculated by the SIMPLER-algorithm on a collocated non-orthogonal grid. It is used to adjust the velocity field to satisfy the conservation of mass (Patankar, 1980). For the computational calculations, a computer code was prepared in FORTRAN-90. In the numerical calculation, a $146 \times 21$ grid arrangement is found to be sufficient for a grid-independent solution, following which the $2 \mathrm{D}$ algebraic grid is generated. 


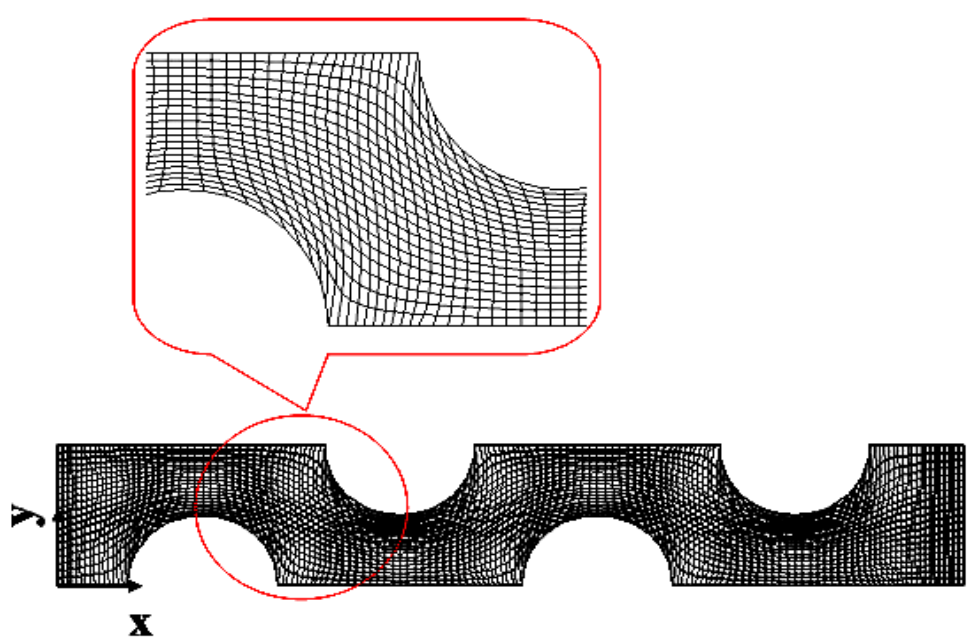

Figure 2. Schematic of grid systems generated by body-fitted coordinates.

\section{VALIDATION}

The numerical model was validated against previously published benchmark problems. The fluid flow and heat transfer over a row of staggered circular tubes subjected to constant wall temperature and constant heat flux were predicted. The Nusselt number for the fully developed region between two tubes subjected to constant wall temperature was obtained from previous literature. Figure 3 shows a comparison between the present study with previous literature (Buyruk, 2002; Kaptan, Buyruk, \& Ecder, 2008) for the local Nusselt number with $\operatorname{Re}=120, \operatorname{Pr}=0.71$, and $S_{T} / D=2.0$. It can be seen that excellent agreement is achieved between the present results and the numerical results of Buyruk (2002) and Kaptan et al. (2008), for the local Nusselt number distribution circumference of the first tube.

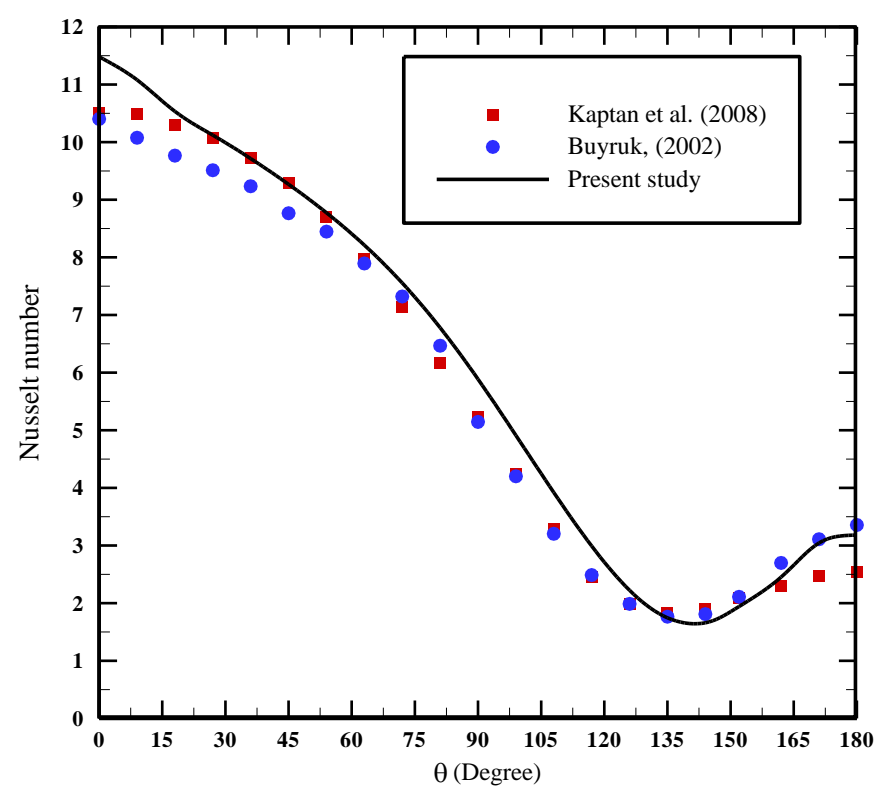

Figure 3. Comparison between the present study with previous literature (Buyruk, 2002; Kaptan et al., 2008) for local Nusselt number with $\operatorname{Re}=120, \operatorname{Pr}=0.71$ and

$$
S_{T} / D=2.0
$$




\section{RESULTS AND DISCUSSION}

Numerical solutions are obtained of the convective heat transfer of a cross-tube staggered bundle, in which the transverse pitch $\left(S_{T}\right)$ is varied between 1.25, 1.5, and 2.0. The range of Reynolds numbers is 25 to 250 . Heat flux $\left(\mathrm{q}_{\mathrm{f}}\right)$ in the surface tubes also varies between 50,100 , and $130 \mathrm{~W} / \mathrm{m}^{2}$. The normalized temperature lines (isotherms) are presented in the temperature distributions within a range of 0 to 1 . Figures $4-6$ show the temperature distribution for various ratios of longitudinal pitch to tube diameter $S_{T} / D$, Reynolds numbers, and heat flux in the tube surface.

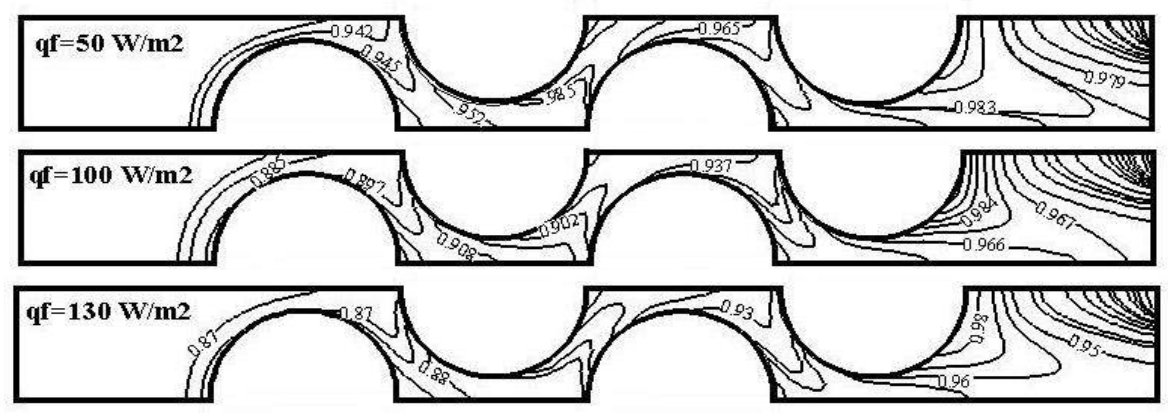

(a)
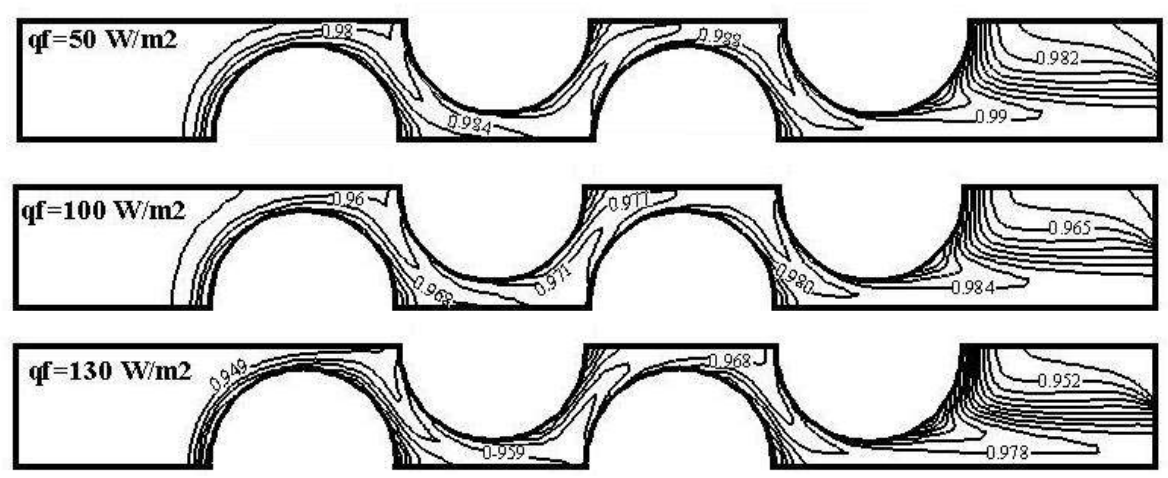

(b)
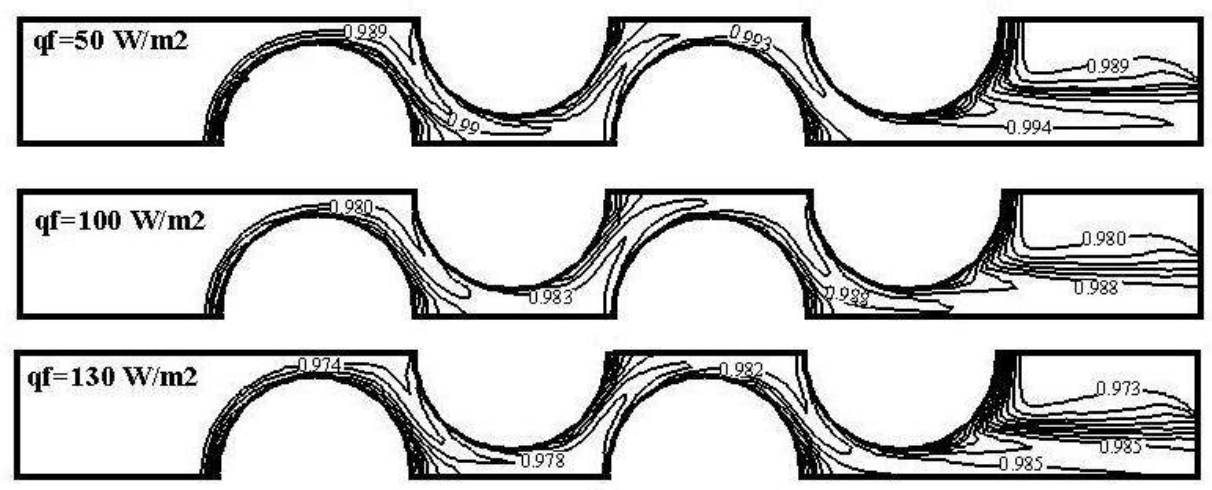

(c)

Figure 4. Isothermal line at $S_{T} / D=1.25$ and Reynolds number of (a) 25, (b) 100, and (c) 250. 
The plots exhibit low fluid temperature at the inlet increasing as the fluid reaches the hot tube surface, revealed by the wavy motion of the stream and the isolation of the separation zone behind the cylinder. The temperature contours are packed on the upstream surface and are diffused downstream. In the separation zone, the thermal layer is relatively thick, particularly near the separation point. As the Reynolds number increases, the lower value isotherms penetrate deeper, which means the colder fluid is getting closer to the hot surface; because of this behavior, the heat transfer is increased.

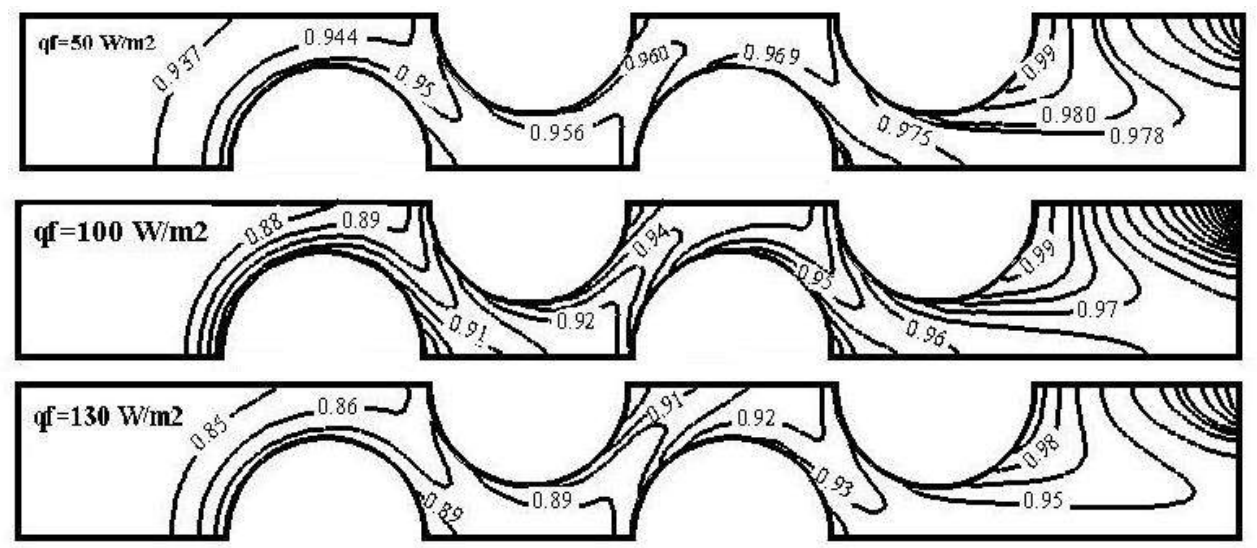

(a)
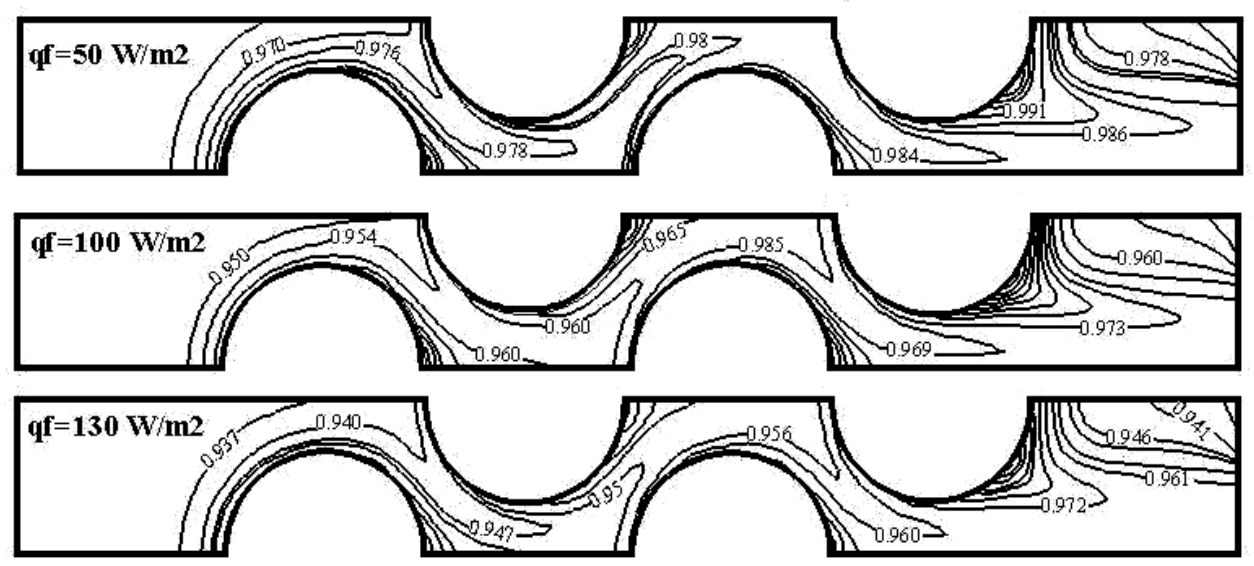

(b)
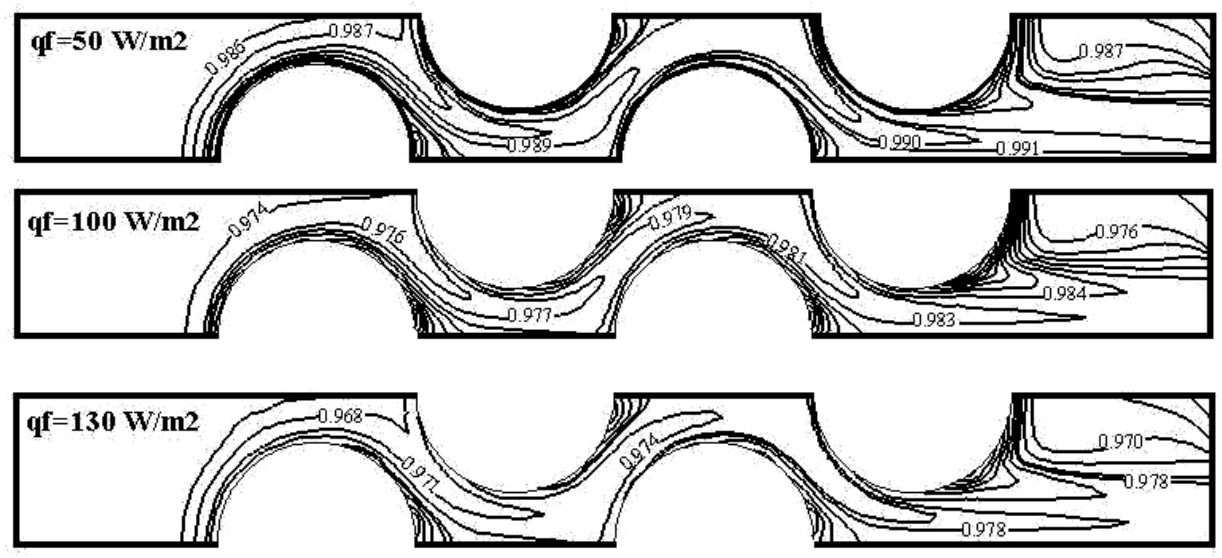

Figure 5. Isothermal line at $S_{T} / D=1.50$ with Reynolds number of (a) 25, (b) 100, and (c) 250 . 

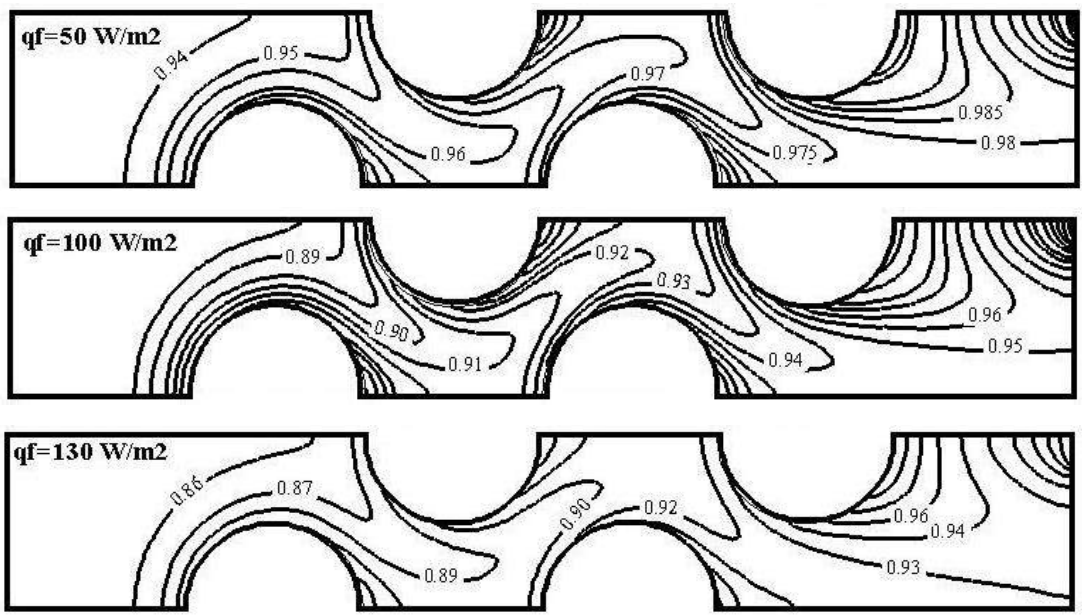

(a)
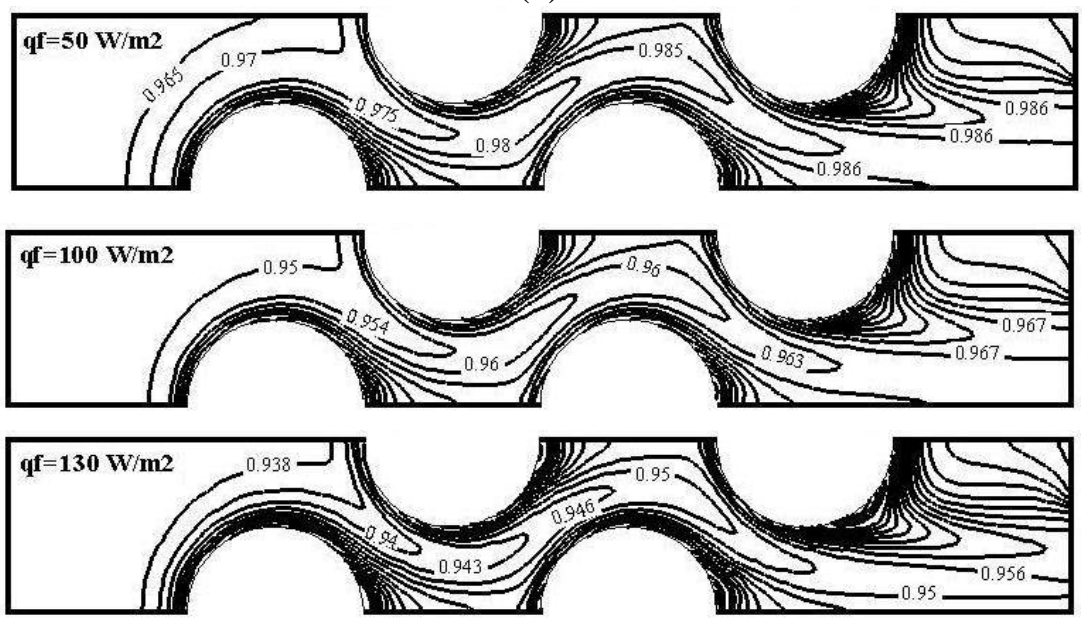

(b)
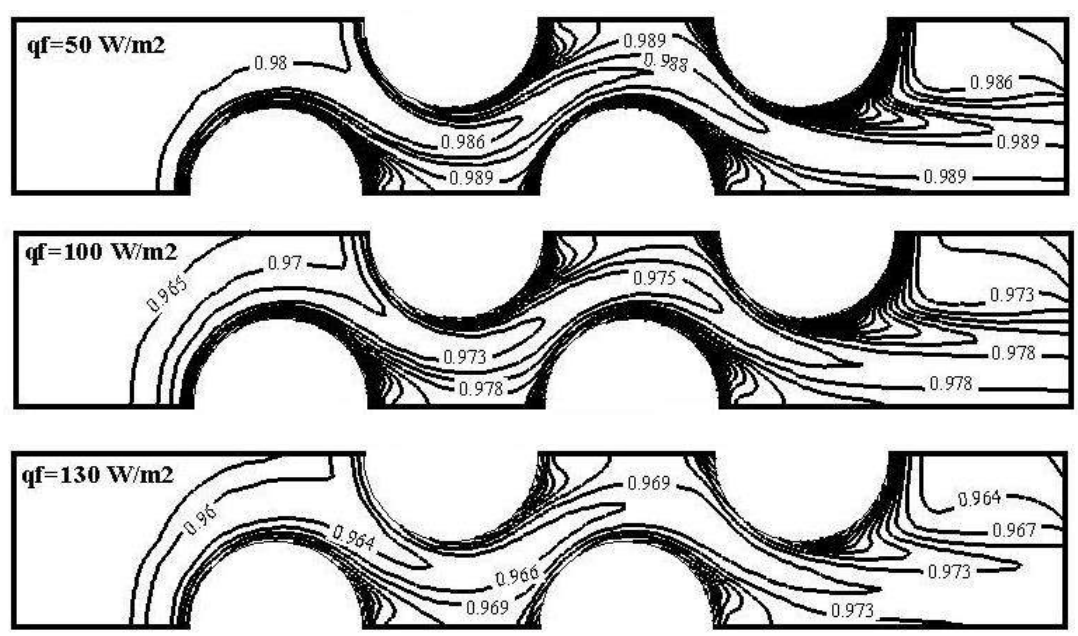

(c)

Figure 6. Isothermal line at $S_{T} / D=2.0$ and Reynolds number for (a) 25, (b) 100, and (c) 250. 
Figure 7 presents the relationship between the local Nusselt number and the angle of a round tube surface for various Reynolds number and locations of the tube. A laminar boundary layer develops from the front stagnation point for a cylinder in crossflow and grows in thickness around the cylinder. The maximum heat transfer rate is located close to the front stagnation point, and the local Nusselt number decreases with the angle. The position of the minimum local Nusselt number is not fixed around 153 deg. at $R e=25,140 \mathrm{deg}$. at $R e=100$, and $135 \mathrm{deg}$. at $R e=250$. It is noted that the minimum values of the local Nusselt number are at the third and fourth tubes. Figure 8 presents the effect of the mean Nusselt number with Reynolds number for the first tube at $\operatorname{Pr}=0.71$. It can be seen that the mean Nusselt number is increased with the increase of Reynolds number. Furthermore, as the ratio of longitudinal pitch to tube diameter $S_{T} / D$ increases, the variation in Nusselt number becomes more significant for a higher Reynolds number.

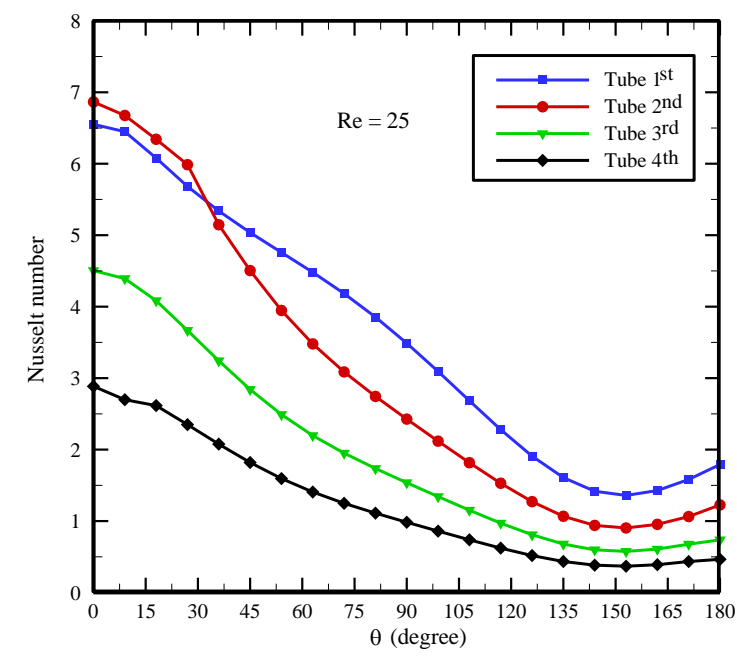

(a)

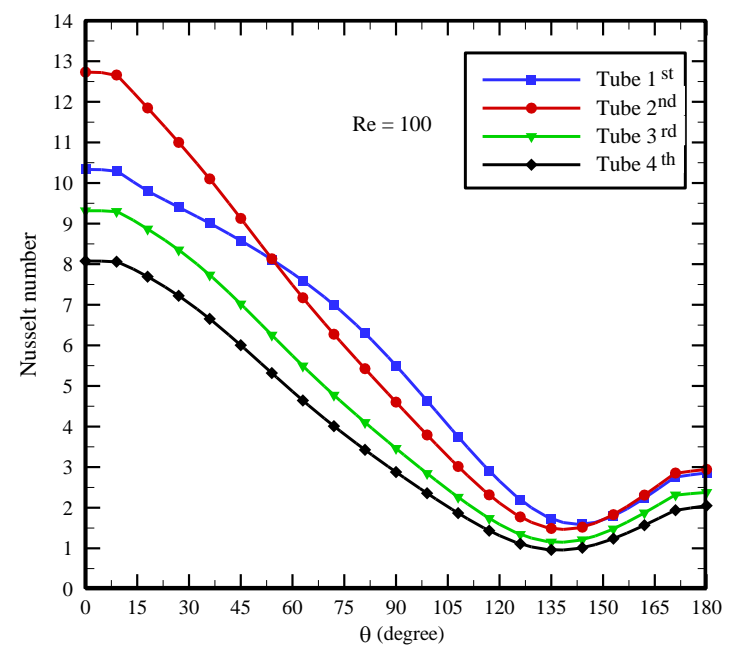

(b)

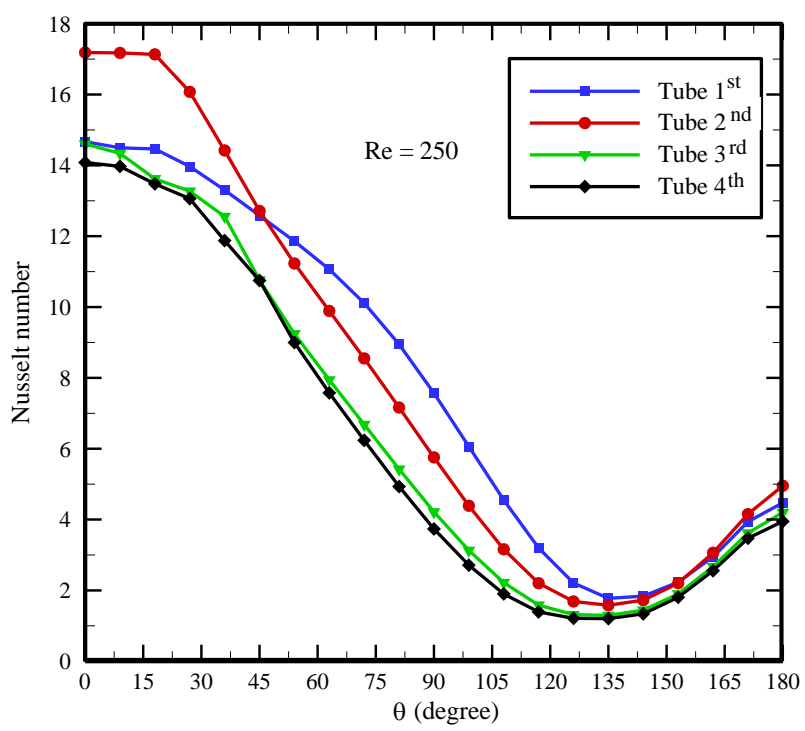

(c)

Figure 7. Local Nusselt number distribution at the surface angle of the tube for $S_{T} / D=$ 2.0, for Reynolds number of (a) 25, (b) 100, and (c) 250 . 


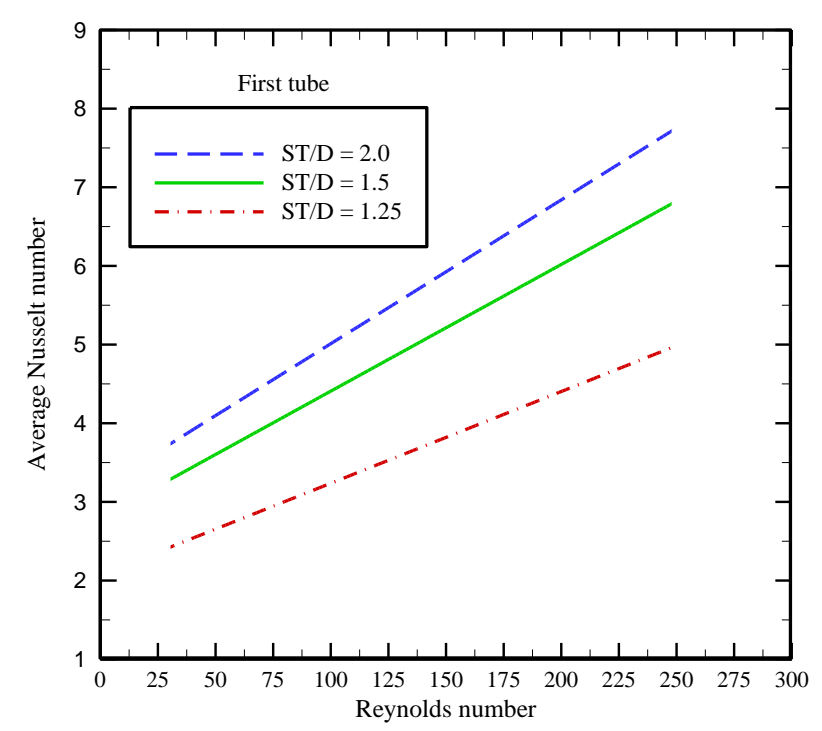

Figure 8. Variation of average Nusselt number with Reynolds number for the first tube at $\operatorname{Pr}=0.71$ with change of transverse pitch.

\section{CONCLUSION}

The flow of fluids and the heat transfer in tubes in the regulation of cross-flow are of great importance in many engineering applications. Two-dimensional steady state and incompressible laminar flow is investigated numerically for staggered tube arrays in cross-flow. A finite difference method is used numerically to solve the governing Navier-Stokes and energy equations. The results show that the behavior of flow and heat transfer of the first tube is similar to the behavior of flow and heat transfer of a single tube. The form of flow and temperature distribution is affected by the Reynolds number.

\section{ACKNOWLEDGEMENTS}

The authors gratefully acknowledge the Faculty of Mechanical Engineering in Universiti Malaysia Pahang (UMP) and the financial support under project no. RDU120103. Also, the first author wishes to express many thanks to Dr. Ahmed W. Mustafa (Tikrit University, Iraq).

\section{REFERENCES}

Al-Doori, W. H. A. R. (2011). Enhancement of natural convection heat transfer from the rectangular fins by circular perforations. International Journal of Automotive and Mechanical Engineering, 4, 428-436.

Bejan, A. (2004). Convection heat transfer. New York, USA: John Wiley \& Sons Inc.

Buyruk, E. (1999). Heat transfer and flow structures around circular cylinders in crossflow. Turkish Journal of Engineering and Environmental Sciences, 23, 299-315.

Buyruk, E. (2002). Numerical study of heat transfer characteristics on tandem cylinders, inline and staggered tube banks in cross-flow of air. International Communications in Heat and Mass Transfer, 29(3), 355-366. 
Buyruk, E., Johnson, M. W., \& Owen, I. (1998). Numerical and experimental study of flow and heat transfer around a tube in cross-flow at low Reynolds number. International Journal of Heat and Fluid Flow, 19(3), 223-232.

Chang, Y., Beris, A. N., \& Michaelides, E. E. (1989). A numerical study of heat and momentum transfer for flexible tube bundles in cross-flow. International Journal of Heat and Mass Transfer, 32(11), 2027-2036.

Chen, C. J., \& Wung, T. S. (1989). Finite analytic solution of convective heat transfer for tube arrays in cross-flow: Part II-Heat transfer analysis. Journal of Heat Transfer 111, 641-648.

Fowler, A. J., \& Bejan, A. (1994). Forced convection in banks of inclined cylinders at low Reynolds numbers. International Journal of Heat and Fluid Flow, 15(2), 90-99.

Incropera, F. P., Dewitt, D. P., Bergman, T. L., \& Lavine, A. S. (2007). Fundamentals of heat and mass transfer. $6^{\text {th }}$ ed. New York: John Wiley \& Sons Inc.

Kaptan, Y., Buyruk, E., \& Ecder, A. (2008). Numerical investigation of fouling on cross-flow heat exchanger tubes with conjugated heat transfer approach. International Communications in Heat and Mass Transfer, 35(9), 1153-1158.

Khan, W. A., Culham, J. R., \& Yovanovich, M. M. (2006). Convection heat transfer from tube banks in cross-flow: Analytical approach. International Journal of Heat and Mass Transfer, 49(25-26), 4831-4838.

Liang, C., \& Papadakis, G. (2007). Large eddy simulation of cross-flow through a staggered tube bundle at subcritical Reynolds number. Journal of Fluids and Structures, 23(8), 1215-1230.

Mandhani, V. K., Chhabra, R. P., \& Eswaran, V. (2002). Forced convection heat transfer in tube banks in cross-flow. Chemical Engineering Science, 57(3), 379391.

Marchi, C. H., \& Hobmeir, M. A. (2007). Numerical solution of staggered circular tubes in two-dimensional laminar forced convection. Journal of the Brazilian Society of Mechanical Sciences and Engineering, 29(1), 42-48.

Matos, R. S., Vargas, J. V. C., Laursen, T. A., \& Bejan, A. (2004). Optimally staggered finned circular and elliptic tubes in forced convection. International Journal of Heat and Mass Transfer, 47(6-7), 1347-1359.

Matos, R. S., Vargas, J. V. C., Laursen, T. A., \& Saboya, F. E. M. (2001). Optimization study and heat transfer comparison of staggered circular and elliptic tubes in forced convection. International Journal of Heat and Mass Transfer, 44(20), 3953-3961.

Naga Sarada, S., Sita Rama Raju, A. V., Kalyani Radha, K., \& Syam Sunder, L. (2012). Augmentation of turbulent flow heat transfer in a horizontal tube with varying width twisted tape inserts. International Journal of Automotive and Mechanical Engineering, 6, 797-810.

Patankar, S. V. (1980). Numerical heat transfer and fluid flow. USA: Hemisphere, Washington, DC.

Rahmani, R., Mirzaee, I., \& Shirvani, H. (2005). Computation of a laminar flow and heat transfer of air for staggered tube arrays in cross-flow. Iranian Journal of Mechanical Engineering, 6(2), 19-33.

Rosdzimin, A. R. M., Zuhairi, S. M., \& Azwadi, C. S. N. (2010). Simulation of mixed convective heat transfer using lattice Boltzmann method. International Journal of Automotive and Mechanical Engineering, 2, 130-143. 
Stanescu, G., Fowler, A. J., \& Bejan, A. (1996). The optimal spacing of cylinders in free-stream cross-flow forced convection. International Journal of Heat and Mass Transfer, 39(2), 311-317.

Syam Sundar, L., \& Sharma, K. V. (2011). Laminar convective heat transfer and friction factor of $\mathrm{Al}_{2} \mathrm{O}_{3}$ nanofluid in circular tube fitted with twisted tape inserts. International Journal of Automotive and Mechanical Engineering, 3, 265-278.

Tahseen, T. A., Ishak, M., \& Rahman, M. M. (2012a). Analysis of laminar forced convection of air for cross-flow over two staggered flat tubes. International Journal of Automotive and Mechanical Engineering, 6, 753-765.

Tahseen, T. A., Ishak, M., \& Rahman, M. M. (2012b). A numerical study of forced convection heat transfer over a series of flat tubes between parallel plates. Journal of Mechanical Engineering and Sciences, 3, 271-280.

Tahseen, T. A., Ishak, M., \& Rahman, M. M. (2013). A numerical study laminar forced convection of air for in-line bundle of cylinders cross-flow. Asian Journal of Scientific Research, 6, 217-226.

Thompson, J. R., Warsi, Z. U. A., \& Martin, C. W. (1985). Numerical grid generation, foundations and applications. New York, USA: North-Holland.

Wang, M., \& Georgiadis, J. G. (1996). Conjugate forced convection in cross-flow over a cylinder array with volumetric heating. International Journal of Heat and Mass Transfer, 39(7), 1351-1361.

Wilson, A. S., \& Bassiouny, M. K. (2000). Modeling of heat transfer for flow across tube banks. Chemical Engineering and Processing, 39(1), 1-14.

Yoo, S. Y., Kwonb, H. K., \& Kim, J. H. (2007). A study on heat transfer characteristics for staggered tube banks in cross-flow. Journal of Mechanical Science and Technology, 21, 505-512.

Yuan, Z. X., Tao, W. Q., \& Wang, Q. W. (1998). Numerical prediction for laminar forced convection heat transfer in parallel-plate channels with streamwiseperiodic rod disturbances. International Journal for Numerical Methods in Fluids, 28, 1371-1387.

\section{NOMENCLATURES}

\begin{tabular}{|c|c|c|c|}
\hline$C_{P}$ & specific heat, $\mathrm{J} / \mathrm{Kg} \mathrm{K}$ & $J$ & Jacobian of the transformation \\
\hline$D$ & diameter of tube, $\mathrm{m}$ & $\overline{N u}$ & local and average Nusselt number \\
\hline $\begin{array}{l}G_{1}, \\
G_{2}\end{array}$ & contravariant velocity components & $p$ & pressure, $\mathrm{N} / \mathrm{m}^{2}$ \\
\hline$h, \bar{h}$ & $\begin{array}{l}\text { local and average convection he-at } \\
\text { transfer coefficient, } \mathrm{W} / \mathrm{m}^{2} \mathrm{~K}\end{array}$ & $P$ & dimensionless pressure \\
\hline$k$ & $\begin{array}{l}\text { thermal conductivity of the fluid } \\
\mathrm{W} / \mathrm{m} \mathrm{K}\end{array}$ & $\operatorname{Pr}$ & Prandtl number \\
\hline$q_{f}$ & heat flux, $\mathrm{W} / \mathrm{m}^{2}$ & $\theta$ & dimensionless temperature \\
\hline$R e_{D}$ & $\begin{array}{l}\text { Reynolds number based on tube } \\
\text { diameter }\end{array}$ & $\mu$ & dynamic viscosity, $\mathrm{N} \mathrm{s} / \mathrm{m}^{2}$ \\
\hline 1 & temperature, ${ }^{\circ} \mathrm{C}$ & $v$ & kinematic viscosity, $\mathrm{m}^{2} \mathrm{~s}$ \\
\hline$S$ & source term & $\rho$ & density $\mathrm{kg} / \mathrm{m}^{3}$ \\
\hline$S_{I}$ & longitudinal distance between two & $\varsigma, \eta$ & curvilinear coordinates \\
\hline
\end{tabular}


consecutive tubes, $\mathrm{m}$

\begin{tabular}{|c|c|c|c|}
\hline$S_{T}$ & $\begin{array}{l}\text { transverse distance between two } \\
\text { consecutive tubes, } m\end{array}$ & $\phi$ & general dependent variable \\
\hline$u, v$ & velocity components, $\mathrm{m} / \mathrm{s}$ & $\begin{array}{l}\alpha, \\
\beta, \gamma\end{array}$ & the coefficients of transformation \\
\hline$U, V$ & $\begin{array}{l}\text { dimensionless velocity } \\
\text { components }\end{array}$ & $\varphi$ & boundary contour \\
\hline$x, y$ & Cartesian coordinates, $\mathrm{m}$ & \multicolumn{2}{|c|}{ Subscripts } \\
\hline$X, Y$ & $\begin{array}{l}\text { dimensionless Cartesian } \\
\text { coordinates }\end{array}$ & $\infty$ & free stream \\
\hline \multicolumn{2}{|c|}{ Greek symbols } & $s$ & $\begin{array}{l}\text { the infinitesimal distance on the } \\
\text { contour }\end{array}$ \\
\hline $\begin{array}{l}\alpha \\
\Gamma\end{array}$ & $\begin{array}{l}\text { thermal diffusivity, } \mathrm{m}^{2} / \mathrm{s} \\
\text { diffusion coefficient }\end{array}$ & $w$ & wall of tube \\
\hline
\end{tabular}

